\title{
COPIM•
}

\section{Year 2 of COPIM: what have we achieved?}

\section{Lucy Barnes}

Published on: Oct 26, 2021

DOI: 10.21428/785a6451.be873035

License: Creative Commons Attribution 4.0 International License (CC-BY 4.0). 


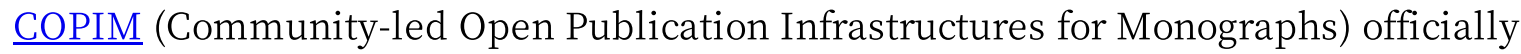
began its work two years ago on 1 November 2019. Funded by Research England and Arcadia Fund, COPIM is an international partnership of researchers, universities, librarians, open access book publishers and infrastructure providers who are building community-owned, open systems and infrastructures to enable open access book publishing to grow and flourish, according to the principles of scaling small. 1

The project is funded for three years, and this is a summary of our second year of activities. (A summary of our first year can be viewed here.) Read on to find out more about our work over the last twelve months, and how you can get in touch.

N.B. The main page of our Open Documentation site is organised by quarters, so, if you prefer, you can browse our outputs and announcements as they happened. We have also published a public version of our full Annual Report to our funders, if you want to dig into a more detailed summary.

\section{Major Achievements}

During the second year of the project, COPIM has continued its work in the areas of collaborative research, infrastructure development, project management and outreach and community building. Further evolving its approach to cope with the continued and compounding challenges that the COVID-19 pandemic and Brexit have offered to the Higher Education sector and beyond, the project has succeeded in meeting the vast majority of its deliverables and milestones across all work packages, in some areas even outperforming the initial goals set. 

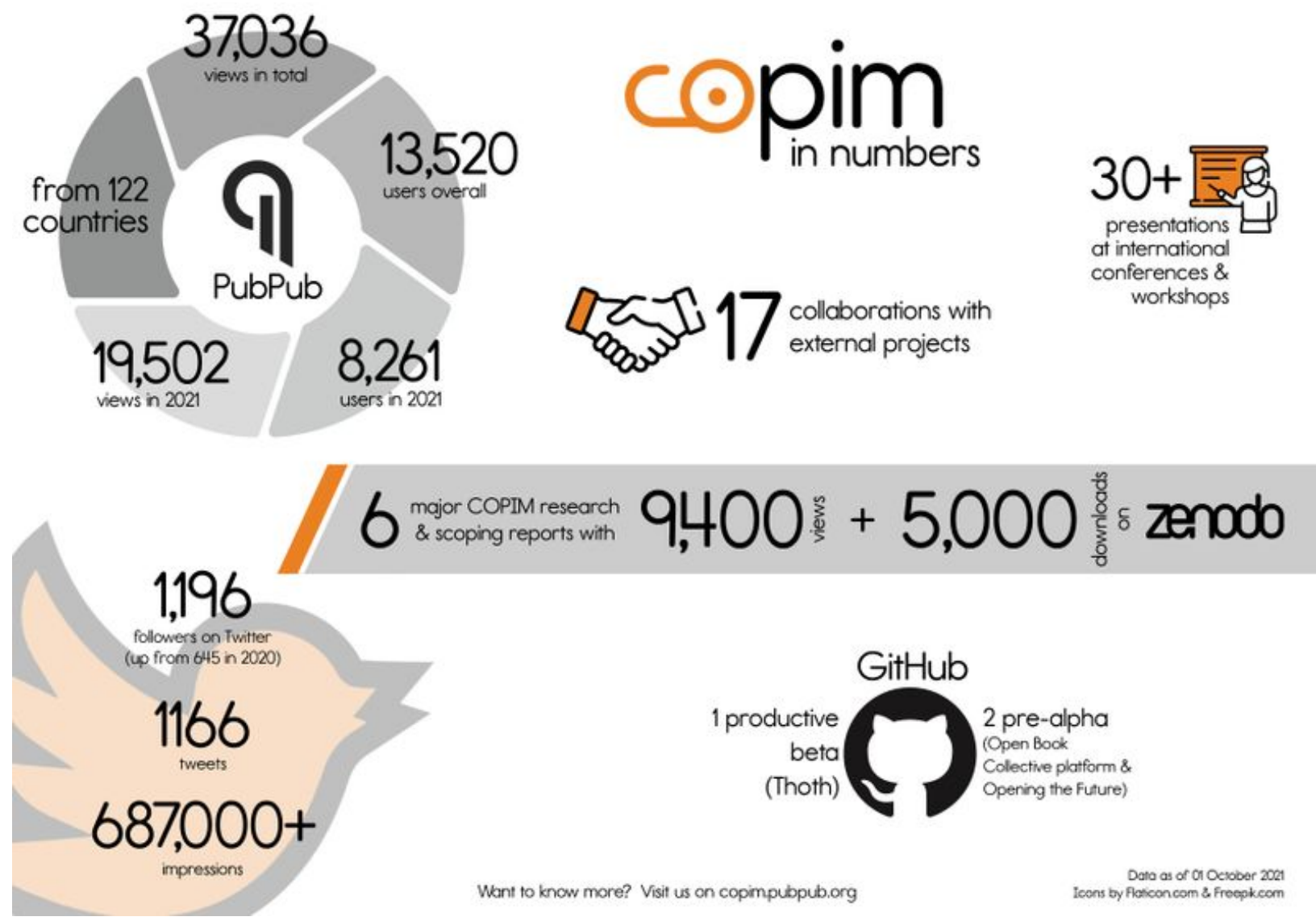

COPIM in numbers, by Tom Grady, CC BY

The list of key output and activities delivered includes the:

- publication of six major scoping reports, comprising the:

- WP2 Scoping Report The Promise of Collaboration: Collective Funding Models and the Integration of Open Access Books into Libraries;

- WP2 Scoping Report Academic Libraries and Open Access Books in Europe: a Landscape Study,

- WP4 Research Report Exploring Models for Community Governance;

- WP6 Research and Scoping Report Books Contain Multitudes: Exploring Experimental Publishing;

- WP6 Research Report Promoting and Nurturing Interactions with Open Access Books: Strategies for Publishers and Authors;

- A substantial update to the WP5 Scoping Report Building an Open Dissemination System.

- The highly successful implementation of COPIM's Opening the Future model whereby library members pay a small annual fee to get unlimited multi-user access to 
eBooks from the publishers' backlists, and the membership revenue is then used to produce new OA monographs. This model does not use BPCs (Book Processing Charges, a per-book fee model). It has been adopted by two publishers - Central European University Press and Liverpool University Press - and library membership uptake has already accrued enough funding for 5 monographs. The model was also a finalist at the ALPSP 'Innovation in Publishing' Awards;

- Early discussions with libraries regarding the Oppen Book Collective platform and model are similarly garnering a lot of interest;

- The successful organisation and documentation of 15 workshops overall, through which COPIM has engaged with more than 190 national and international stakeholders from the UK, US, Africa, Latin America, Australia, New Zealand, and Europe to establish communities on a variety of overarching open access book-related topics;

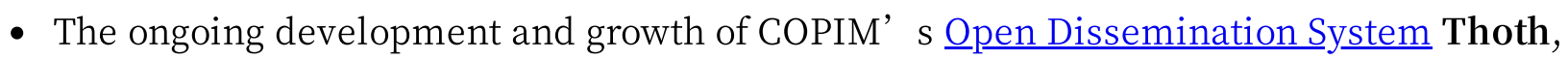
a tool and service to make open access book metadata available in an open and transparent way, and successful real-life implementation thereof with four OA book publishers;

- The setup and iterative extension of a set of Outreach and Dissemination activities that are combining a variety of channels including social media and open community platforms;

- The development of three Pilot Projects of experimental books, co-created with international communities of scholars and three scholar-led presses: Open Humanities Press, Open Book Publishers, and Mattering Press.

The COPIM project has continued and deepened its engagement with the work packages' variety of stakeholders (i.e., librarians, publishers, researchers, technology providers, and the general public), bringing together key experts and those interested in learning more about scholar-led, not-for-profit, OA book publishing. Alongside its own event organisation and outreach activities, COPIM has been involved in the $\underline{\text { pen Access }}$ Book Network, while COPIM team members have been invited to participate in a variety of external conferences, events, and networks by organisations and projects such as Invest in Open Infrastructure, OASPA, OPERAS, LIBER, the Next Generation Libraries Publishing project, OpenAIRE, The British Library, COAR, EIFL, and the European Open Science Cloud. 
In addition to that, notable collaborations were sought with e.g. the European Science Cloud's Provider Marketplace and EOSC Pillar; the German Federal Ministry for Education and Research-funded projects KOALA, CODRIA, and Scholar-led Plus, the German scholar-led.network initiative, LYRASIS, and the Embedding Preservability. project.

The sustained progress against the original plan during this second year is particularly noteworthy as the project had to work with the continued and compounding effects of the various challenges that COPIM saw in its first-year set-up. As already outlined during the first year Brexit and the pandemic - and the systemic effects these events continue to have on the Higher Education sector as a whole - governed much of the project work on COPIM. As a result, the project had to accommodate further delays in staff recruitment and an increase in pandemic-related limitations to availability of staff members due to extended care duties and the toll on health of all involved.

Despite these challenges COPIM, together with its stakeholders, is now well positioned to implement the open infrastructures and systems of governance conceptualised over its first two years, while continuing to develop its research and project management structures. COPIM has requested a six-month no-cost extension from its funders to make effective use of budget underspend accrued during the project' $s$ lifetime because of the pandemic, and to enable the team to continue its work on the envisioned open infrastructures for monographs.

\section{Get in touch}

- If you are a library interested in subscribing to Opening the Future or a press interested in implementing it, or if you would like to know more about this particular model, visit https://openingthefuture.net/ or email oppeningTheFuture@copim.ac.uk.

- Libraries and presses interested in learning more about COPIM's collaborative multistakeholder collective and platform, please get in touch with COPIM's Work Package 2 viawp2@copim.ac.uk.

- Presses interested in learning more about Thoth, COPIM's open metadata system, please visit thoth.pub, or contact wp도이.ac.uk.

- And researchers, presses, and libraries interested in experimental approaches to longform publishing in the Humanities and Social Sciences, please explore our recent report, visit copim.pubpub.org/work-package-6 or get in touch with wp6@@opim.ac.uk.

- Finally, if you would like to learn more about the project as a whole, email info@copim.ac.uk, visit www.copim.ac.uk or our Open Documentation site at copim.pubpub.org/, and follow us on Twitter@COPIMproject. 


\section{Consortial Members of COPIM}

COPIM is an international partnership comprising

- universities: Coventry University, Birkbeck, University of London, Lancaster University, and Trinity College, Cambridge

- established scholar-led open access presses, represented through the ScholarLed consortium, which consists of Open Book Publishers, punctum books, Oppen Humanities Press, Mattering Press, and meson press;

- libraries: University of California Santa Barbara (UCSB) Library, Loughborough University Library, the British Library;

- infrastructure providers: the Directory of Open Access Books (DOAB), Jisc루울

- and membership organisations: the Digital Preservation Coalition.

\section{Contact COPIM}

- Email: info@copim.ac.uk

- Twitter:@COPIMproject

- Website: https://www.copim.ac.uk/

- Open documentation site: https://copim.pubpub.org/

Header photo by Lindsay Henwood on $\underline{\text { Uns }} \underline{\text { Llash }}$

\section{Footnotes}

1. This "principle eschews standard approaches to organisational growth that tend to flatten community diversity through economies of scale, and instead puts forward the idea that scale can be nurtured through intentional collaborations between communitydriven projects that promote a bibliodiverse ecosystem while providing resilience through resource sharing and other kinds of collaboration" (Adema and Moore, 2021).

2. See also Robertson (2021) Supporting open access monographs without the costs of book processing charges. Jisc Research. $\_$ 